But in the one area of product standards that something could be done, and done quickly, our regulatory body the GDC seems to have acquired a scotoma. Now I am not talking here about toothbrushes and tubes of toothpaste but about the products manufactured in dental laboratories and prescribed by dental surgeons on a daily basis. Where is the product standard that ensures every denture, crown, bridge or other fixed or moveable dental prosthesis is fit for purpose? Indeed where is the basic definition of 'clinical fit' recorded to validate the claims that 'all my caps fit and patients wear them'!

But now of course we have access to technology that measures in microns and displays on computer screens graphic pictures of the truly awful quality of far two many impressions of equally awful clinical preparations. And so at the very outset the chances of a dental technologist being able to craft a properly fitting prosthesis are often reduced to zero.

A major trade supplier has recently claimed in sales literature supporting the use of their intra-oral scanner that nearly $60 \%$ of dental impressions are unsatisfactory .

I myself have carried out a random survey of more than 6,000 dental impressions and of the 100 cases that I subjected to audit can confirm this supplier's figure is very close to mine at $52 \%$. This is a shocking indictment.

At the time of writing, my letter and a reminder to the President of the GDC requesting the introduction of quality based product standards remain unanswered and the 6,000 word paper I wrote in response to the GDC's invitation to comment on their 'Standards on Commissioning and Manufacturing Dental Appliances' has been ignored. Sadly Professor Richards I feel that whilst the patient may be hungry for better quality our professional representatives seem unwilling to create the recipe.

N. J. Knott Chippenham DOI: 10.1038/sj.bdj.2009.1022

\section{TRULY AMAZING}

Sir, another issue of the $B D J$ and another letter/opinion paper by Mr Mew (Accepting responsibility; BDJ 2009; 207: 194).
There are so many complaints that he voices in this latest one that it would be impractical to address them all but let me address one. He is sure that surgery can be avoided by his "natural growth guidance' but we should not forget that orthognathic surgery is almost exclusively carried out in adults after the majority of growth has ceased so, if he could demonstrate that growth can be promoted in an adult patient, this would be truly amazing. I suspect though that he cannot.

From hearing Mr Mew present cases in the past I am fairly certain that he is in fact utilising normal growth at around the growth spurt as is the case in countless orthodontic practices around the country and world whenever a functional appliance is fitted. I await the deliberations of the GDC with interest.

A. Pearson

Oxford

DOI: 10.1038/sj.bdj.2009.1023

\section{A LITTLE HASTY}

Sir, Roberts and Lucas offer a spirited defence of dental age assessment ( $B D J$ 2009; 207: 251-253), but their assurance that informed consent is always obtained for this procedure is perhaps a little hasty. They state that 'all the subjects seen by our DAA team give informed consent'. This may be true inasmuch as they have been given enough information and know what they are agreeing to, but sufficient information is only one of the three necessary criteria for valid consent: the other two are competence and voluntariness.

Even if we grant that competence is not an issue here (although it could be, given that children are involved), the fact remains that asylum seekers may be faced with torture or death if they are deported. Given these alternatives, it could be argued that they are being coerced into consenting to something that they are told will help their application for asylum. In this sense, it is quite possible that the voluntariness criterion for consent is not being met by dental age assessment in some cases, despite the obvious importance of the procedure.

\section{Shaw}

Glasgow

DOI: $10.1038 /$ sj.bdj.2009.1024

\section{LYME DISEASE WARNING}

Sir, I would like to raise the awareness and knowledge of the profession as to the effects of Lyme disease/Borreliosis and associated infections, both at a personal level and also to patients. I have gleaned much personally after suffering, undiagnosed, for the previous 11 years.

Lyme disease is a spirochete infection (Borrelia), classically after a tick bite. In many ways progress of the infection may be compared to three phases of syphilis. Initially, an erythema migrans around the bite, then general flu-like symptoms in the following weeks and finally the third stage: fatigue, sweats, chills, muscleskeletal pain and weakness, neuropathies and a bucketful of other multisystemic problems including palsies and dental pains as well as some psychological issues. If the infection is diagnosed early and treated, then that may be the end of it, however, some 5-20\% of individuals go on to develop the tertiary phase.

From personal experience it is like trying to work as though your latex gloves were now heavy duty marigolds; unable to hold an air-rotor for more than a five minute stretch, and with difficulty even keeping your foot depressed on a floor pedal. Power naps at every down time during the day; an inability to sit on an operating chair for any period without back or neck pain becoming a distraction. The list could go on. Then the irritability, paranoia and depressions kick in. Dentistry becomes impossible and then you get a diagnosis of depression, signed off work and eventually retire.

In general, Bell's palsy is widely reported, but I have been unable to find figures for the occurrence with this condition. Dropping eyelids, unilateral or bilateral can also be features as can sinusitis and middle ear infections. Orally, there can be dry mouth and thirst and widespread tooth sensitivity even if there seems to be perfect gingival health, intense and at times total pulpitis of all teeth, as though hit by two upper cuts.

Although much is non-specific, and far from comprehensive, it should be acknowledged and I hope this might be of help to readers.

L. K. Riley

Bournemouth

DOI: 10.1038/sj.bdj.2009.1025 